\title{
A DINÂMICA DA IMIGRAÇÃO LABORAL INTERNACIONAL CONTEMPORÂNEA: O CASO DO VALE DO TAQUARI/RS NO PERÍODO DE 2010-2018
}

Rosmari Terezinha Cazarotto ${ }^{2}$ Fernanda Cristina Wiebusch Sindelar ${ }^{3}$

\begin{abstract}
Resumo: Este artigo tem por objetivo analisar a dinâmica laboral e o perfil dos trabalhadores imigrantes internacionais inseridos no mercado formal de trabalho na região do Vale do Taquari-RS, no período de 2010 a 2018. O trabalho caracteriza-se como um estudo exploratório, de natureza quanti-qualitativa, e foi realizado com base em dados secundários provenientes da Relação Anual de Informações Sociais (RAIS), seguido de análise qualitativa tendo como foco o processo de inserção dos imigrantes recentes no mercado de trabalho formal. A partir do estudo desenvolvido, observa-se que desde 2010 a região tem atraído um contingente significativo de imigrantes laborais internacionais, especialmente haitianos do sexo masculino, que atuam sobretudo na indústria de transformação em vagas demandadas por empresas.
\end{abstract}

Palavras-chave: Migrações internacionais. Dinâmica laboral. Vale do Taquari.

\section{THE DYNAMICS OF CONTEMPORARY INTERNATIONAL LABOR IMMIGRATION: THE CASE OF VALE DO TAQUARI/RS IN THE PERIOD 2010- 2018}

\begin{abstract}
This paper aims to analyze the labor dynamic and the profile of international immigrants workers that are inserted in the formal labor market, in the region of Vale do Taquari-RS during period of 2010 to 2018 . The paper is characterized as an exploratory study, with quantitative and qualitative nature. It was carried out based on secondary data, originated from the Annual List of Social Information - Relação Anual de Informações Sociais (RAIS), proceeding with qualitative analysis, focusing on the process of insertion of recent immigrants into the formal labor market. From the developed study, it is observed that since 2010 the region has attracted a significant contingent of international immigrants, especially Haitians, male, who work especially in the manufacturing industry, for the jobs opportunities demanded by companies.
\end{abstract}

Keywords: International migrations. Labor dynamic. Vale do Taquari.

\footnotetext{
${ }^{1}$ Este artigo é parte dos resultados do projeto de pesquisa Cidades médias e os fluxos imigratórios internacionais recentes: o exemplo da cidade de Lajeado na Região do Vale do Taquari-RS, financiado pelo CNPq (Conselho Nacional de Desenvolvimento Científico e Tecnológico) do Brasil no triênio 2019-2022 (processo 408687/2018-5), com apoio institucional da Univates. 2 Universidade do Vale do Taquari - Univates, Centro de Ciências Humanas e Sociais, Lajeado, Brasil, rosmari.cazarotto@univates.br, https://orcid.org/0000-0001-8072-7346

${ }^{3}$ Universidade do Vale do Taquari - Univates, Centro de Gestão Organizacional, Lajeado, Brasil, fernanda@univates.br, https://orcid.org/0000-0003-3138-7386
} 


\section{LA DINÁMICA DE LA INMIGRACIÓN LABORAL INTERNACIONAL CONTEMPORÁNEA: EL CASO DEL VALE DO TAQUARI/RS EN EL PERÍODO 2010-2018}

Resumen: Este artículo tiene como objetivo analizar el trabajo y el perfil de los trabajadores inmigrantes internacionales insertados en el mercado laboral formal en la región de Vale do Taquari-RS en el período comprendido entre 2010 y 2018 . El trabajo se caracteriza por ser un estudio exploratorio, de naturaleza cuantitativa y cualitativa. Se realizó con base en datos secundarios accedidos por RAIS, procedido de un análisis cualitativo, enfocado en el proceso de inserción de inmigrantes recientes en el mercado laboral formal. Del estudio desarrollado, se observa que desde 2010 la región atrajo a un contingente significativo de inmigrantes internacionales, especialmente haitianos, hombres, que trabajaban en la industria manufacturera, en las ofertas de empleo demandadas por las empresas.

Palabras clave: Migraciones internacionales. Dinámica laboral. Vale do Taquari.

\section{Introdução}

Em termos globais, o fluxo de migrações internacionais intensificou-se desde o início do XXI, apresentando novas dinâmicas em comparação ao que se observou nos séculos anteriores. Os motivos que levavam habitantes de determinadas regiões a procurarem novos destinos para se estabelecer mudaram, tornando este um tema atual, complexo e desafiador (BÓGUS; FABIANO, 2015).

De maneira geral, observa-se que os grandes fluxos migratórios internacionais acompanham o cerne do sistema capitalista, de tal maneira que em épocas de mudanças nas dinâmicas das economias há também alterações nas motivações que levam as pessoas a migrar e na forma de mobilidade e deslocamento.

No período de 2000 a 2014, o Brasil esteve em um processo de expansão econômica, aproximando-se de uma situação de pleno emprego em algumas regiões. Isso proporcionou uma maior visibilidade do país em âmbito internacional e fez com que se tornasse um destino atraente para os estrangeiros. Dentro do país, algumas regiões passam a ser mais atraentes para o estabelecimento de imigrantes, sendo uma delas o Vale do Taquari (VT), no Rio Grande do Sul (CAZAROTTO; MEJÍA, 2018), foco deste estudo.

A região, formada por 36 municípios e situada na porção central do estado (Figura 1), acompanhou o processo nacional de expansão econômica: várias empresas locais tiveram suas plantas produtivas ampliadas e a busca por mão de obra tornou-se constante. Como consequência, nos últimos anos o Vale do Taquari tem recebido um significativo fluxo migratório internacional. Constatou-se que, de 
2010 a 2018, o fluxo de imigrantes internacionais ingressantes na região foi de 2.395 pessoas, conforme informações sistematizadas a partir da obtenção de dados junto ao Ministério da Justiça e Segurança Pública, por meio do SISMIGRA e do Observatório de Migrações Internacionais (OBMigra) (BRASIL, 2019a).

Figura 1 - Localização do Vale do Taquari - RS

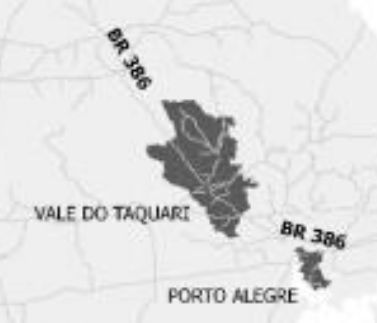

Fonte: Adaptado de CODEVAT (2017).

Atualmente, os contingentes migratórios para o VT que se destacam em termos de quantidade são os grupos latino-americanos. Esse panorama é diferente do contexto das migrações que se observaram nesta região nos séculos XIX e início do século $X X$, quando predominavam os grupos europeus formados especialmente por açorianos, alemães e italianos (BARDEN et al., 2001).

Diante desse cenário, questiona-se: como esses migrantes têm se inserido na dinâmica laboral da região? Qual é o perfil dos trabalhadores estrangeiros e em quais setores eles estão se inserindo localmente? Buscando responder a essas questões, este artigo tem por objetivo analisar a dinâmica laboral e o perfil dos trabalhadores imigrantes internacionais no mercado formal de trabalho na região do Vale do Taquari/RS a partir de 2010. 
O artigo divide-se em quatro seções. Na primeira, faz-se uma revisão de literatura destacando características e motivações para a ocorrência de fluxos migratórios internacionais contemporâneos. $\mathrm{Na}$ segunda, apresentam-se os procedimentos metodológicos utilizados para a realização do trabalho. Na terceira seção faz-se a análise dos dados e reflexões acerca da dinâmica laboral observada na região em estudo e, por fim, apresentam-se as considerações finais deste trabalho.

\section{Migrações internacionais: dinâmicas e motivações}

As migrações internacionais não são acontecimentos recentes, fazem parte da trajetória da humanidade. Em termos de quantidade, atualmente, a população mundial em situação de mobilidade humana internacional formaria o quinto maior país do mundo, representando $3,5 \%$ da população mundial e ultrapassando 270 milhões de pessoas. Em 1970, os imigrantes representavam aproximadamente 2,3\% (POVOA NETO, 2020). Atualmente, a população mundial em situação de mobilidade humana internacional formaria o quinto maior país do mundo.

De acordo com a conjuntura histórica e os interesses nacionais, o conteúdo da experiência migratória vai se modificando. A presença de imigrantes no território nacional é normatizada a partir de instrumentos jurídicos e políticos do Estadonação, os quais podem restringir ou não o ingresso de imigrantes (SAYAD, 1998). Além disso, com as mudanças advindas do meio técnico-científico-informacional, as alterações no processo migratório se dão também nas formas de deslocamento, nas possibilidades de comunicação e nas motivações que levam as pessoas a migrar.

Ao analisar as migrações à luz das fronteiras nacionais, de acordo com Sayad (1998), emigrante e imigrante são o mesmo sujeito. Migrar é um fato social total, que inclui dentro do processo uma dimensão diacrônica e uma sincrônica, que equivale considerar tanto a história quanto a estrutura social. $\mathrm{Na}$ construção de um quadro teórico analítico pertinente às migrações, no final do século XIX, estudos pioneiros do geógrafo Ernest Georg Ravenstein (1834-1913) tiveram um carácter proeminente. Ravenstein criou os fundamentos referentes às áreas de atração e de repulsão, tendo como princípios as vantagens e desvantagens econômicas, sociais e laborais em relação ao local de partida e ao local de chegada. Esse aporte teórico contemplava tanto as migrações de curta como as de longa distância, com algumas diferenciações no perfil dos migrantes (UEBEL, 2015). 
Na década de 1970, ao analisar o fenômeno das migrações internacionais, o geógrafo francês Pierre George toma como base critérios jurídicos, e uma das categorias que distingue é a do trabalhador estrangeiro. Argumenta que este preenche vazios prejudiciais ao funcionamento do sistema econômico, ao mesmo tempo em que busca complementar os meios de existência para si próprio e para a família, uma vez que não tem esperança de fazer isso no seu país de origem. É um imigrante temporário, introduzido por um contrato num mercado de trabalho (GEORGE, 1977, p. 13). Para o autor, os países receptores beneficiam-se de uma força de trabalho criada fora de suas fronteiras e ainda têm à sua disposição uma mão de obra abundante para os trabalhos que os nacionais não querem realizar.

Para além de explicações de repulsão e atração e dinâmicas econômicas, Sassen (2010) questiona por que algumas pessoas que vivem em condições semelhantes não migram. Nesse sentido, a explicação teórica de George é importante, mas não suficiente para explicar o fenômeno. Para Sassen, variáveis adicionais como recrutamento por empregadores ou a decisão da família de que um de seus membros deve emigrar devem ser consideradas.

Assim, na contemporaneidade, diante das novas dinâmicas dos imigrantes internacionais, a teoria para compreender a experiência desse processo tem aportado ainda a perspectiva do transnacionalismo. Conforme Ramos (2012), uma das marcas do atual sistema-mundo é a construção de um mercado de trabalho global e do cidadão transnacional. O migrante internacional passa a ser compreendido no contexto de suas múltiplas relações: familiares, econômicas, organizacionais, religiosas e sociais no âmbito local e global. Ao mesmo tempo em que tem múltiplos pertencimentos, à medida que se estabelece em um lugar passa a manter forte conectividade com sua terra natal, contribuindo não apenas com o seu desenvolvimento, mas também com o da localidade de instalação.

Adicionalmente, não é possível, na contemporaneidade, entender o contexto local sem relacioná-lo com o âmbito global. Muito do que se vivencia na escala local são repercussões das transformações oriundas do processo de globalização, viabilizado pela revolução técnico-científica e informacional e pela construção de processos políticos, a partir da década de 1970. A globalização consolidou-se na produção e nos territórios e hoje constitui-se em um paradigma para compreensão dos diversos aspectos da realidade (SANTOS, 2006). É favorecida por um conjunto de técnicas que, pela primeira vez, envolvem o planeta inteiro, porém que não se espalham igualmente, isto é, as ações que asseguram a inserção da produção no 
mercado global acontecem nos territórios em que há uma infraestrutura técnicocientífico-informacional instalada. Com isso, todos os lugares podem fazer uso do mesmo momento, a partir de um deles e/ou a partir de múltiplos lugares (SANTOS, 2006).

Politicamente, mesmo que os mecanismos de territorialização do capital sejam distintos, as premissas neoliberais alcançam todos os lugares e atingem tanto as grandes cidades como as pequenas (SCHILLER; ÇAGLAR, 2011). Na visão destes autores, há um reposicionamento de espaços urbanos dentro da hierarquia de poder político e econômico, regional, nacional e global no qual as cidades de pequena escala "downscaled cities", definidas, não pelo tamanho físico e populacional, se inserem neste processo. Os migrantes internacionais têm se tornado, cada vez mais, atores significativos na reestruturação econômica e política das cidades ao redor do mundo (MEJIA; CAZAROTTO; ROGERIO, 2018).

Nesse novo patamar da mundialização, criam-se as condições para a aproximação dos lugares e a aceleração dos fluxos de pessoas, culturas e bens. Novas dinâmicas globais conectadas se estabelecem, dentre elas a econômica, a partir da internacionalização dos negócios, com seus respectivos produtos (SASSEN, 2010). A globalização não gera a homogeneização global, mas reestrutura as diferenças espaciais devido às suas especialidades e acentua as desigualdades (SANTOS, 2006).

Para Damiani (2011), a migração precisa ser compreendida não só como deslocamento humano, mas como irradiação geográfica de um sistema econômico. No passado, atendia à reprodução da força de trabalho nas propriedades rurais, e hoje atende às empresas nacionais e transnacionais. Em consonância, Póvoa Neto (1997) propõe o enfoque da migração na perspectiva do conceito de mobilidade do trabalho. Sayad (1998) também argumenta que a principal razão da permanência do estrangeiro no local de imigração é o trabalho, logo, sua presença é de caráter provisório. O trabalho é o que faz existir o imigrante, não qualquer trabalho, mas "o trabalho para imigrantes".

De acordo com Piore (1979), os imigrantes se adaptam mais facilmente às condições do mercado de trabalho intensivo. Muito trabalhadores locais desprezam tais postos por serem de baixa remuneração, baixo status e baixa possibilidade de evolução profissional, porém são atrativos para os imigrantes quando vislumbram a possibilidade de ganhar mais do que seu em país de origem. O autor chamou este 
tipo de posto de trabalho de secundário, diferenciando-o do posto primário, o qual caracterizou-o como mais qualificado, com mecanismos de promoção e carreira.

Contudo, conforme Borjas (2012) ao perceber que as amenidades locais são piores do que o esperado, os trabalhadores recém migrados tem muita chance mudar para outro local, ocasionando a repetição da migração. Para Kenneth e Vanderkamp (1986) o estímulo para a repetição da migração "repeated migration" podem vir das oscilações da economia contribuindo para que os imigrantes optem por novamente inserirem-se no curso migratório buscando outros destinos no país ou mesmo incorporando-se novamente nas rotas internacionais em busca de novas oportunidades que os lugares possam lhes oferecer.

Para Sassen (1988), a tecnologia da informação conferiu dinâmica à produção e aos lugares. As conexões criadas pela internacionalização da produção, orientada à exportação, por exemplo, contribuíram para a circulação de trabalhadores como um dos fluxos no espaço transacional.

Uma nova geografia de centros e margens transpassa a velha linha divisória entre países ricos e pobres. A mobilidade internacional da força de trabalho acompanha a grande reestruturação do capitalismo, iniciada nos anos 1970, expressa na reestruturação produtiva e nas concentrações urbanas (PIORE,1979). No século XXI, tais transformações conectam todos os sistemas de cidades, de diferentes escalas, porém o capital é seletivo, elege áreas e se concentra em lugares onde as condições técnicas existem.

Além disso, no cenário da globalização, há uma pressão crescente entre empresas e países para reduzir os custos e permanecer competitivos. A diminuição de custos se torna uma variável que pode contribuir para a criação de condições que demandam o recrutamento de trabalhadores imigrantes a baixos salários, o que é reforçado pelo contexto de enfraquecimento dos sindicatos (SASSEN, 2010).

Piore (1979) analisou que os empregadores e os postos de trabalho são os elementos estratégicos para explicar os fluxos massivos de imigrantes. Esse aporte teórico contribui para compreender a realidade dos fluxos migratórios internacionais recentes para o Vale do Taquari, juntamente com os demais citados anteriormente.

No período de 1970 a 2010, o VT passou por uma significativa reestruturação espacial, perceptível a partir das transformações decorrentes da modernização da produção agrícola que os agricultores familiares vivenciaram. Nesse intervalo, ocorreu o fortalecimento das cadeias produtivas de frangos, suínos e leite, as quais passaram a se agregar aos complexos agroindustriais com seus respectivos 
sistemas integrados à indústria de alimentos (BARDEN et al., 2018). As cidades também passaram a ter mais força e projeção. Nesse contexto, a dinâmica econômica regional foi se fortalecendo à medida que a divisão territorial do trabalho, oriunda das empresas locais ligadas ao ramo alimentício, intensificou-se. Ocorreu assim a internacionalização dos produtos fabricados dentro desses complexos agroindustriais.

Assim, observa-se na região em estudo que desde 2010 as agroindústrias regionais vêm absorvendo uma parcela significativa da força de trabalho dos imigrantes internacionais. Isso é consequência da falta de trabalhadores nacionais disponíveis, em função da economia encontrar-se próxima de uma situação de pleno emprego (em 2014), ou, ainda, em função de os trabalhadores nacionais não quererem realizar determinadas funções, conforme destacado por George (1977). Mais adiante, as análises da dinâmica da imigração laboral regional serão aprofundadas.

\section{Procedimentos metodológicos}

A proposta deste trabalho consiste em um estudo exploratório que articula informações de dados quantitativos, obtidos por meio de métodos estatísticos, seguido de análise qualitativa, tendo como foco o processo da inserção dos imigrantes recentes no mercado de trabalho formal na região do Vale do Taquari RS. Conforme Gil (2019, p. 26),

pesquisas exploratórias são desenvolvidas com o objetivo de
proporcionar visão geral, de tipo aproximativo, acerca de determinado
fato. Este tipo de pesquisa é realizado especialmente quando o tema
escolhido é pouco explorado e [...] produto final deste processo passa
a ser um problema mais esclarecido, passível de investigação
mediante procedimentos mais sistematizados.

Pesquisas empíricas que analisam a particularidade da inserção laboral e socioeconômica de imigrantes internacionais na região do Vale do Taquari são ainda incipientes. Nesse sentido, o estudo explora dados secundários, sistematizados a partir da obtenção junto a organismos oficiais como o Ministério da Justiça e Segurança Pública, por meio do Sistema Nacional de Registro Migratório (SISMIGRA) e do Observatório de Migrações Internacionais (OBMigra), desenvolvido em parceria com a UnB (BRASIL, 2019a), e a Relação Anual de Informações Sociais (RAIS), disponibilizada pelo Ministério da Economia (BRASIL, 2019b), com o propósito de compreender a chegada dos imigrantes internacionais a 
partir de 2010 e sua empregabilidade até 2018. A organização dos dados foi feita em planilhas eletrônicas, nas quais foram tabulados e apresentados através de tabelas e gráficos que são apresentados na próxima seção.

A abordagem qualitativa, que também é contemplada no trabalho, analisa como os imigrantes internacionais se inserem no mercado de trabalho dos municípios do VT, interior do Rio Grande do Sul. A coleta de dados aconteceu entre os anos de 2018 e 2019, porém, os dados referem-se ao período entre 2010 e 2018. Além disso, observação participante, entrevistas formais e informais com os imigrantes internacionais, com moradores das cidades que compõem a região, lideranças políticas, empresariais e religiosas também foram utilizadas para qualificar a abordagem do trabalho. Também foram utilizadas matérias de jornais locais: o Informativo, Opinião e A Hora.

Na próxima seção, apresenta-se a análise da dinâmica laboral e o perfil dos trabalhadores imigrantes internacionais no mercado formal de trabalho na região do VT e sua representatividade em nível estadual.

\section{Resultados e discussão}

Nas últimas décadas, a região do VT passou por um contínuo processo de urbanização que, apesar de desigual entre os municípios, foi acompanhado de uma mudança na dinâmica econômica regional. A centralidade dessa dinâmica passou das atividades rurais para as atividades industriais e de serviços, associadas diretamente aos complexos agroindustriais, ao mesmo tempo em que houve uma concentração populacional em algumas cidades (BARDEN et al., 2018). Essas mudanças regionais contribuíram para a vinda de migrantes, tanto nacionais como internacionais, especialmente no período recente, atraídos pelo crescimento econômico e pelas oportunidades no mercado de trabalho.

De acordo com os dados da RAIS, o número de trabalhadores imigrantes internacionais no VT passou de 60, em 2010, para 1.310 em 2018, representando um crescimento de $2.183,3 \%$ no período analisado (Gráfico 1). Em relação ao estado do Rio Grande do Sul, em 2018, essa mão de obra migrante com vínculo formal de trabalho correspondia a $8,47 \%$ do total de mão de obra estrangeira. Em 2010 representava 1,6\% e em 2012 perfazia 2,8\% desse contingente populacional (BRASIL, 2019b). 
Gráfico 1 - Imigrantes laborais internacionais para o VT - 2010/2018

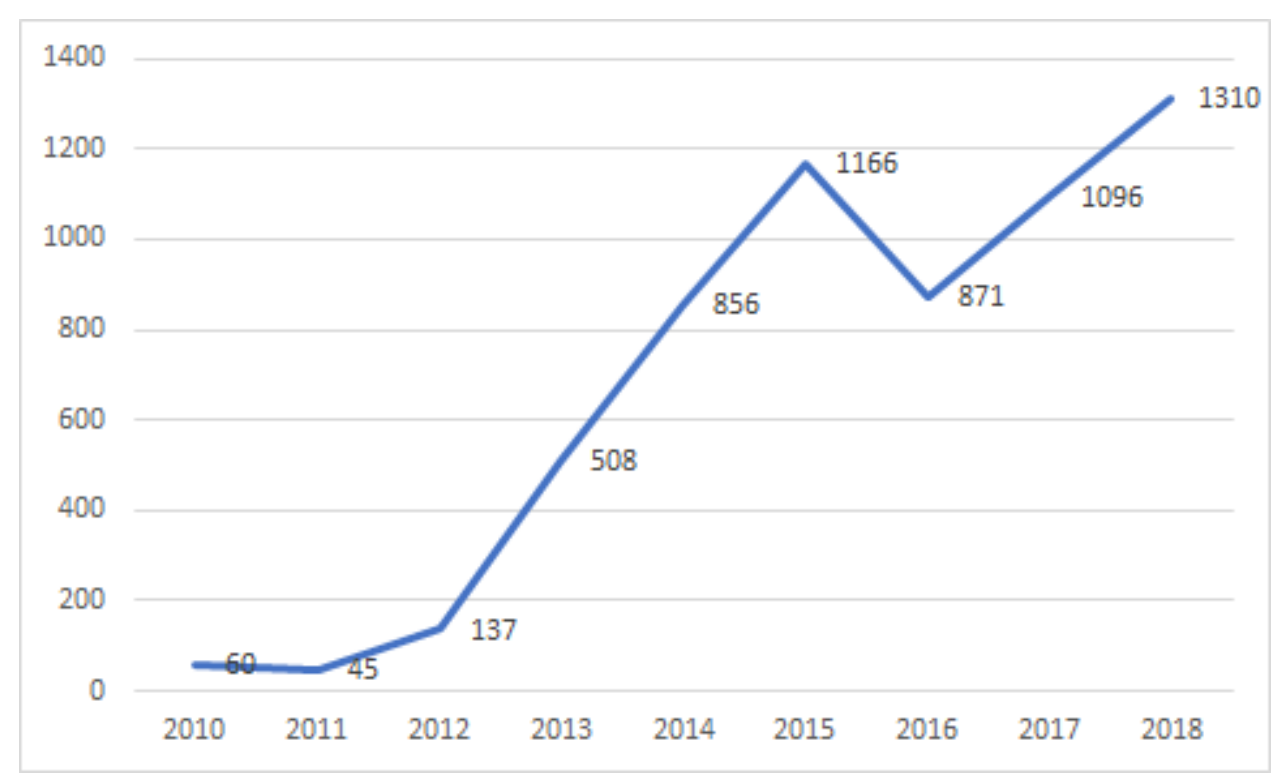

Fonte: Relação Anual de Informações Sociais (RAIS). Dados da pesquisa.

Os dados também revelam algumas situações importantes. Os anos de 2012 e 2013 foram o auge em termos de porcentagem de crescimento dos vínculos formais de trabalho de estrangeiros em relação ao ano de 2011: 204,4\% e 270,8\%, respectivamente (BRASIL, 2019b). Esses foram os anos em que responsáveis por empresas e cooperativas da região se deslocaram até o estado do Acre para recrutar trabalhadores imigrantes haitianos diante da necessidade de mão de obra.

A cidade de Brasileia-AC era a principal porta de entrada de muitos haitianos que procuravam novos espaços de vida, para além das fronteiras de seu país, devido ao abalo sísmico de 7 graus na escala Richter que havia devastado o Haiti em 2010, deixando cerca de 300 mil desabrigados. A reportagem de um jornal local intitulada "Haitianos chegam para trabalhar no Vale do Taquari", veiculada em 2012, demonstra o perfil laboral da chegada desse contingente populacional na região. De acordo com a chefe do departamento pessoal da empresa Cosuel, "aqui os haitianos poderiam reconstruir suas vidas através do trabalho" (O INFORMATIVO, 2012).

A principal nacionalidade estrangeira no mercado de trabalho formal no Vale do Taquari, em 2018, foi de imigrantes haitianos, perfazendo $80,4 \%$ do total, seguida da nacionalidade argentina, com 4,6\%. Os dados informam que haitianos, argentinos, paraguaios, uruguaios e bengaleses estão entre as principais 
nacionalidades no ranking da inserção no mercado de trabalho formal no VT (Gráfico 2).

Gráfico 2 - Principais nacionalidades de trabalhadores formais imigrantes internacionais no VT - 2010 a 2018

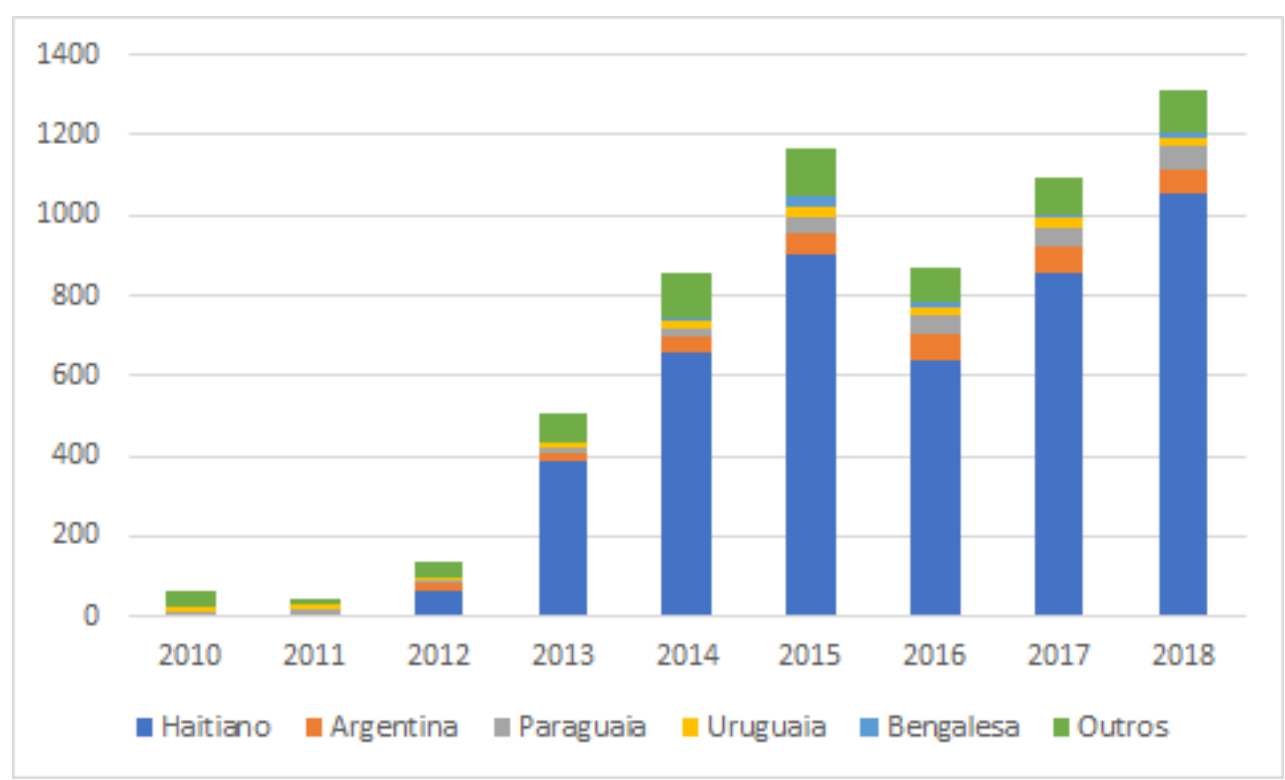

Fonte: Relação Anual de Informações Sociais (RAIS). Dados da pesquisa.

Cabe destacar ainda que o perfil dos migrantes, quanto à nacionalidade, alterou-se no período analisado. Em 2010 e 2011 não existem registros na RAIS da presença de imigrantes laborais haitianos, mas, a partir de 2013, esta nacionalidade superou as demais. Importante mencionar que a nacionalidade haitiana compõe o único grupo de imigrantes que, por razões humanitárias, foi amparado pela Resolução Normativa no 97, de 12 de janeiro de 2012, do Conselho Nacional de Imigração (CNIg) (TONHATI et al., 2016). Aos haitianos foi criado um visto especial, nomeado visto humanitário, concedido a aqueles que não tinham antecedentes penais. Esse canal regular de imigração possibilitou a obtenção de carteira de trabalho e Cadastro de Pessoa Física (CPF).

O relato de uma haitiana, obtido através da pesquisa no município de Arroio do Meio, localizado na região em estudo, revela a importância da obtenção dos documentos na decisão de optar pelo Brasil: "Trabalhei 2 anos no Equador como cuidadora, não tinha papel, documentos (carteira de trabalho), aqui tenho". Em relação à vida que levava no Haiti, relata que "aqui tem seguridade, paz e luz elétrica", revelando outros fatores complementares, além do posto de trabalho. 
Ainda, os Gráficos 1 e 2 apontam um constante crescimento do número de estrangeiros ocupados no mercado de trabalho formal no período analisado, com exceção de 2016, quando houve uma variação negativa significativa, com destaque para os haitianos. De 1.166 trabalhadores internacionais formais em 2015, a região empregou apenas 871 em 2016. Esse decréscimo repercute a crise política e econômica vivenciada pelo Brasil. Muitos optaram por reingressar ao percurso migratório internacional; alguns, inclusive, colocaram a empresa onde atuavam na justiça para obter seus direitos e ir embora do país (CAZAROTTO; MEJíA, 2018).

As incertezas da economia convertem-se em elemento chave que pode motivar a repetição da migração, conforme Kenneth e Vanderkamp (1986). Novamente buscam novos destinos no país ou até mesmo partindo para rotas internacionais do processo migratório em busca de trabalho e vida melhor.

Atrelado à crise política e econômica pela qual o Brasil vem passando desde meados de 2014, juntou-se ainda o desencanto com as expectativas iniciais. Em uma das empresas que mais contrata, por exemplo, os imigrantes receberam aluguel, alimentação e transporte durante os seis primeiros meses, no entanto, passado esse período, esses subsídios foram retirados e, consequentemente, os custos de subsistência aumentaram.

Ademais, observou-se uma valorização do dólar frente ao real ${ }^{4}$. Desde o início do fluxo migratório de haitianos, de 2012 a 2015, o dólar praticamente dobrou de preço, reduzindo a capacidade de repasse de recursos para familiares ainda domiciliados no país de origem. Esse fato, somado às dificuldades que encontram para inserir-se no mercado de trabalho em funções que não sejam específicas para imigrantes (SAYAD, 1998), qual sejam, as que os nativos não querem fazer, contribuiu para que muitos retornassem aos fluxos migratórios internacionais, deixando a região em 2016.

Nesse sentido, em entrevista ao Jornal Opinião, em agosto de 2016, um haitiano declara:

"Víamos aqui como um local cheio de oportunidades, mas, infelizmente, somente em uma área. Sou formado, tenho ensino superior, e por que preciso trabalhar apenas em um determinado serviço? Por que não em outros ramos? Por que as pessoas que se

\footnotetext{
${ }^{4}$ Conforme dados do Banco Central (2020), a cotação média da taxa de câmbio no mês de janeiro de 2012 foi de $\mathrm{R} \$ 1,79$ para cada dólar americano; já em dezembro de 2015, a cada dólar era cotado em média a $R \$ 3,87$. Além disso, vale comentar ainda que no mês de setembro/2015 essa cotação chegou a $R \$ 4,19$, demonstrando que no período mencionado houve uma valorização significativa do dólar americano frente ao real brasileiro.
} 
lembram da mão de obra dos haitianos pensam somente em um local específico?"

A referida edição do jornal teve como capa o destaque "Imigrantes começam a ir embora de Encantado" (BORTOLETTI, 2016). Trata-se de um município situado na região em estudo.

Ao ingressarem novamente na rota da imigração internacional, os estrangeiros tinham como principais destinos o Chile, a Argentina e os Estados Unidos, porém, no ano seguinte, novamente começaram a retornar ao Brasil devido à dificuldade em encontrar trabalho nos outros países e aos processos de deportação, no caso dos EUA. Assim, percebe-se que a partir de 2017 o VT novamente entrou como destino dos imigrantes (Gráfico 2). Esses novos imigrantes estrangeiros são provenientes tanto da rota internacional como da mobilidade interna no Brasil.

Conforme relata Renel Simon, um dos líderes haitianos que trabalha no Centro de Referência de Assistência Social (CRAS) de Lajeado, em uma entrevista dada ao Jornal A Hora em julho de 2019, dez haitianos chegam por semana ao VT, o que revela que o fluxo migratório ainda é intenso ${ }^{5}$ (CHAPARINI, 2019).

Quanto aos setores de atuação, os dados do Gráfico 3 apontam que 82\% dos trabalhadores formais estrangeiros no VT, em 2018, atuavam no setor da indústria de transformação, seguidos de $8 \%$ em serviços, $6 \%$ no comércio e $3 \%$ na construção civil.

Gráfico 3 - Imigrantes internacionais com vínculo formal de trabalho no VT, segundo setores de atuação em 2018

\footnotetext{
${ }^{5}$ De acordo com a referida edição do jornal, a estimativa é de que cerca de 2,4 mil haitianos estejam distribuídos em cinco cidades da região. Em torno de $70 \%$ tem emprego formal. Cerca de 800 vivem em Lajeado; por volta de 500 a 800, em Encantado; cerca de 100, em Teutônia; em torno de 450, em Estrela; e 250, em Arroio do Meio.
} 


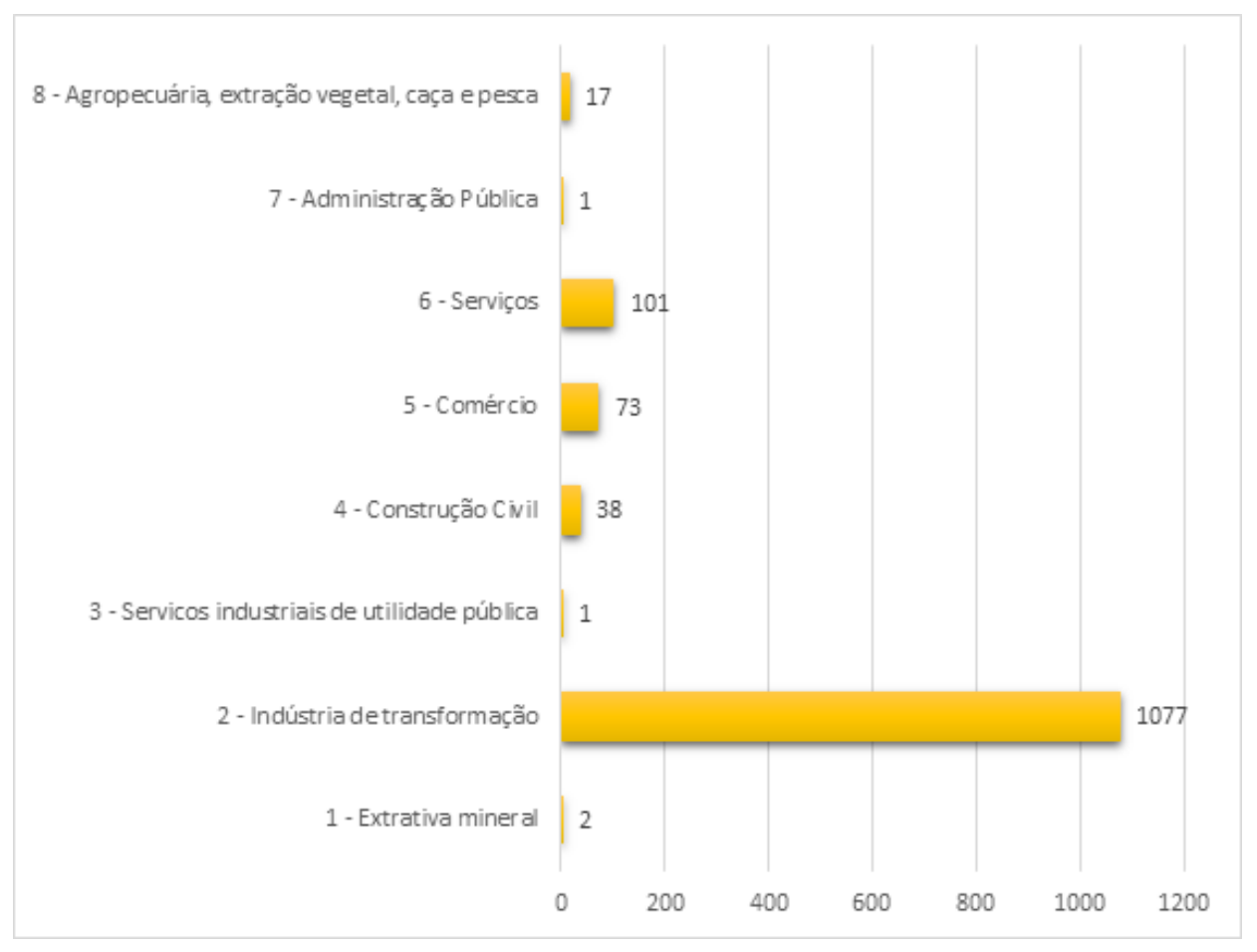

Fonte: Relação Anual de Informações Sociais (RAIS). Dados da pesquisa.

Esses dados caracterizam uma diferenciação da região em relação ao estado do Rio Grande do Sul: 39\% dos imigrantes laborais formais atuavam na indústria de transformação e $29 \%$ no setor de serviços, de acordo com o levantamento de dados da RAIS (BRASIL, 2019b).

A narrativa de Gefrrard, em entrevista à matéria já citada do Jornal A Hora, revela essa desigualdade: "Os imigrantes são bem aceitos enquanto servem como mão de obra braçal na indústria" (CHAPARINI, 2019). Sua fala reflete a dificuldade que os imigrantes internacionais têm de encontrar trabalho que não seja na indústria frigorífica, em especial. As principais funções ocupadas por esses trabalhadores estão associadas ao abate de aves, suínos, processamento de carnes e leite nas agroindústrias locais.

Tal fato é corroborado pela fala de uma moradora local, em entrevista concedida à pesquisa, que vive em uma área da cidade de Lajeado onde residem muitos imigrantes internacionais recentes: "São muito educados, assíduos, queridos, amigos. Trabalham em lugares que os daqui não querem, áreas frias, matar bicho".

$\mathrm{Na}$ variável escolaridade, $48 \%$ dos imigrantes internacionais inseridos no mercado de trabalho formal no VT possuem Ensino Fundamental incompleto e/ou completo; 44\%, Ensino Médio completo e/ou incompleto; 5\%, Ensino Superior incompleto e/ou completo; $4 \%$ são analfabetos, ao passo que apenas um possui 
pós-graduação (doutorado) (Gráfico 4). No Rio Grande do Sul, no mesmo ano, os dados indicaram que os imigrantes possuem, em média, formação mais elevada, já que 34\% afirmou ter Ensino Fundamental incompleto e/ou completo; 49\%, Ensino Médio incompleto e/ou completo; $14 \%$, com Superior incompleto e/ou completo e mais $2 \%$ com pós-graduação (BRASIL, 2019b).

Gráfico 4 - Escolaridade dos imigrantes internacionais com vínculo formal de trabalho no VT - 2018

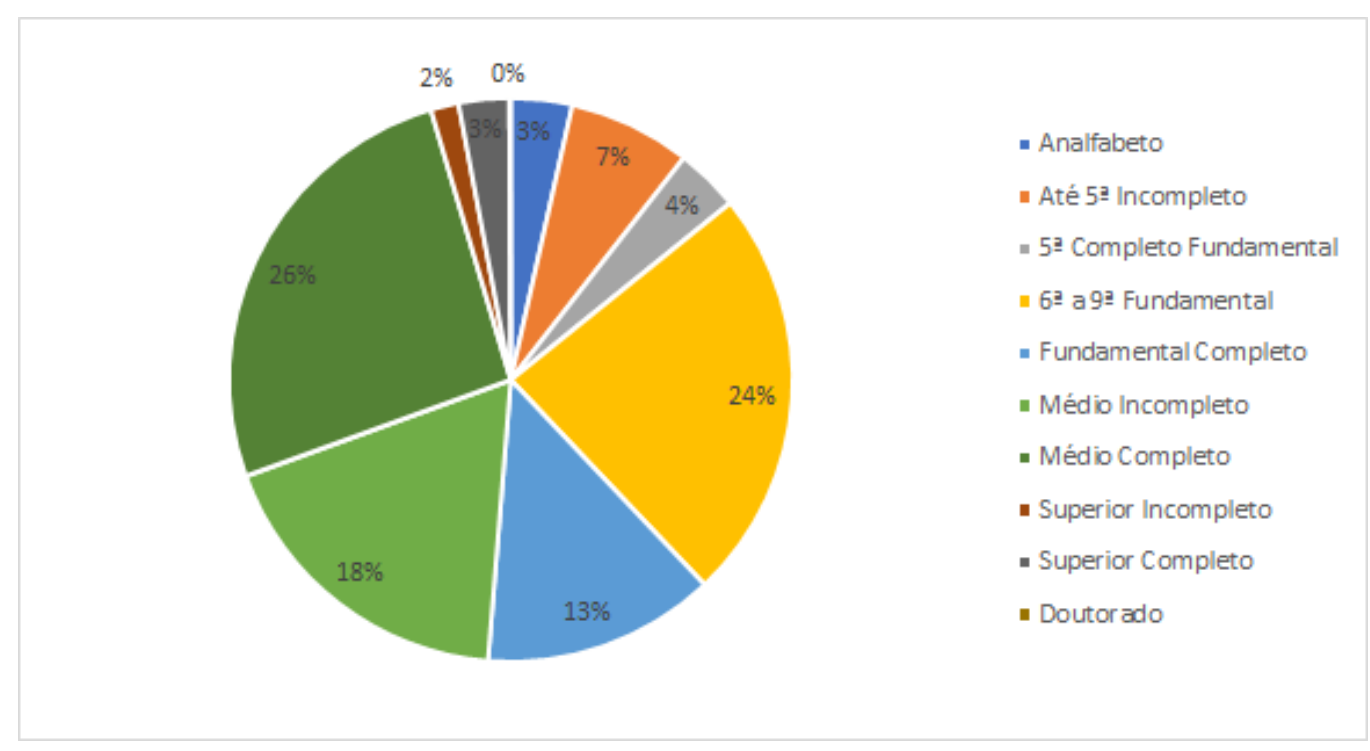

Fonte: Relação Anual de Informações Sociais (RAIS). Dados da pesquisa.

Segundo Borjas (2012), as características demográficas dos trabalhadores, como idade e educação, são muito importantes quando se trata da População Economicamente Ativa (PEA). É comum que a migração aconteça entre trabalhadores mais jovens e qualificados, uma vez que os mais velhos tendem a se mudar menos porque a migração é um investimento em capital humano. Como resultado, os trabalhadores mais velhos têm um período mais curto sobre o qual podem coletar retorno para os investimentos em migração. 
A faixa etária dos imigrantes internacionais com vínculo formal de trabalho no Vale, com maior concentração em 2018, foi de 30 a 39 anos, perfazendo $42 \%$ (Gráfico 5). Contudo, ao somar o intervalo de idades entre 18 a 49 anos, atinge-se $94 \%$ das pessoas, ante $89 \%$ do RS, demonstrando que em termos de faixa etária as diferenças não são muito significativas, e os grupos por faixas etárias se assemelham na região em estudo e no estado (BRASIL, 2019b). Esse fato orienta para o perfil laboral desta população, sendo a composição etária promissora para uma região. É uma força de trabalho criada fora das fronteiras nacionais que beneficia o país receptor por ter à sua disposição uma mão de obra abundante para os trabalhos que os nacionais não querem realizar (GEORGE, 1977).

Gráfico 5 - Faixa etária dos imigrantes internacionais com vínculo formal de trabalho no VT - 2018

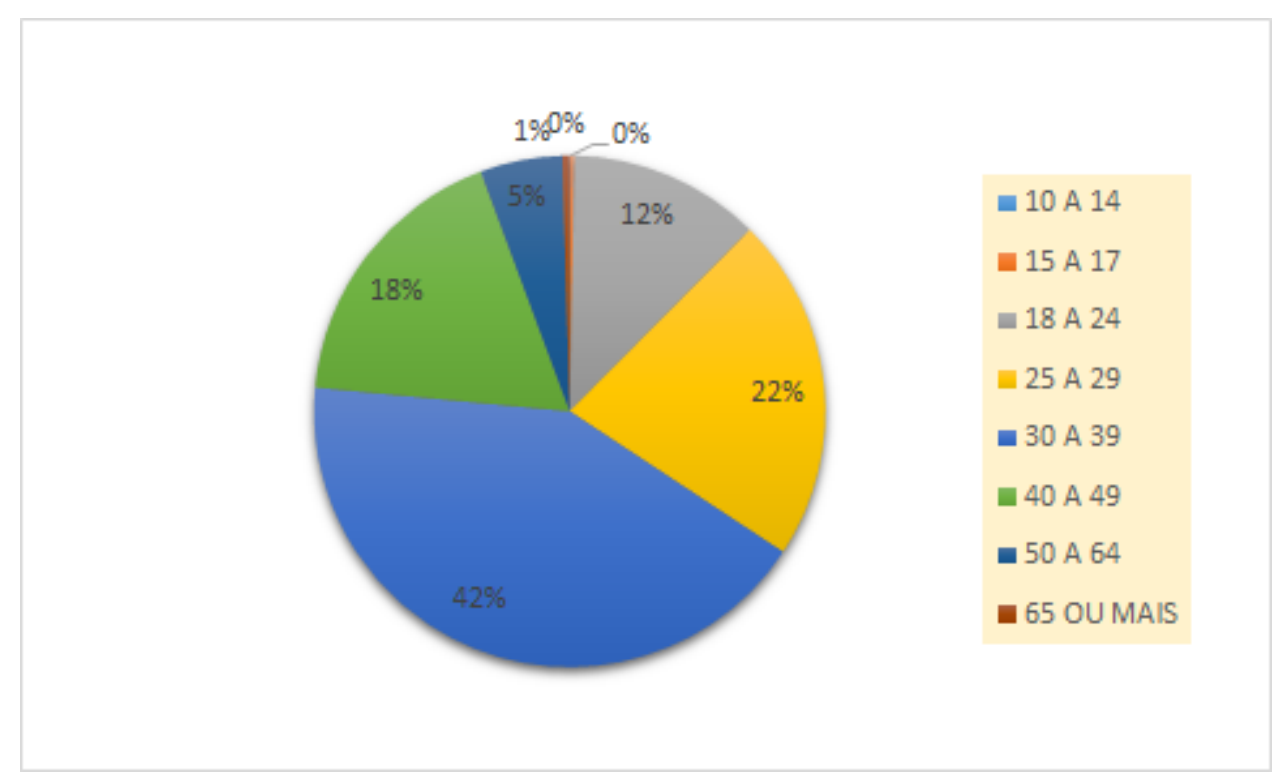

Fonte: Relação Anual de Informações Sociais (RAIS). Dados da pesquisa.

No que refere-se à remuneração média, as informações do Gráfico 6 apontam que $77 \%$ dos imigrantes internacionais com vínculo formal de trabalho no VT, em 2018, receberam de um e meio a dois salários mínimos. Nesse ano, o salário mínimo nacional foi de $R \$ 954,00$, o que significa que esse grupo recebeu entre $R \$$ $1.431,00$ e $\mathrm{R} \$ 1.908,00$. Ademais $11 \%$ receberam de um a um e meio salário (ou seja, até $R \$ 1.431,00)$ e $9 \%$ de dois a três salários mínimos. Em suma, em torno de 
90\% receberam até dois salários mínimos (até $\mathrm{R} \$ 1.908,00$ ), evidenciando uma remuneração relativamente baixa e menor do que a renda nacional, embora não tão distante. Segundo dados da Pesquisa Nacional por Amostra de Domicílios Contínua (PNAD), relativa ao terceiro trimestre de 2019, a renda média do trabalhador com 14 anos ou mais no Brasil é de $\mathrm{R} \$ 2.223,00$ (IBGE, 2019).

Gráfico 6 - Remuneração média, em salário mínimo, dos imigrantes internacionais com vínculo formal de trabalho no VT - 2018

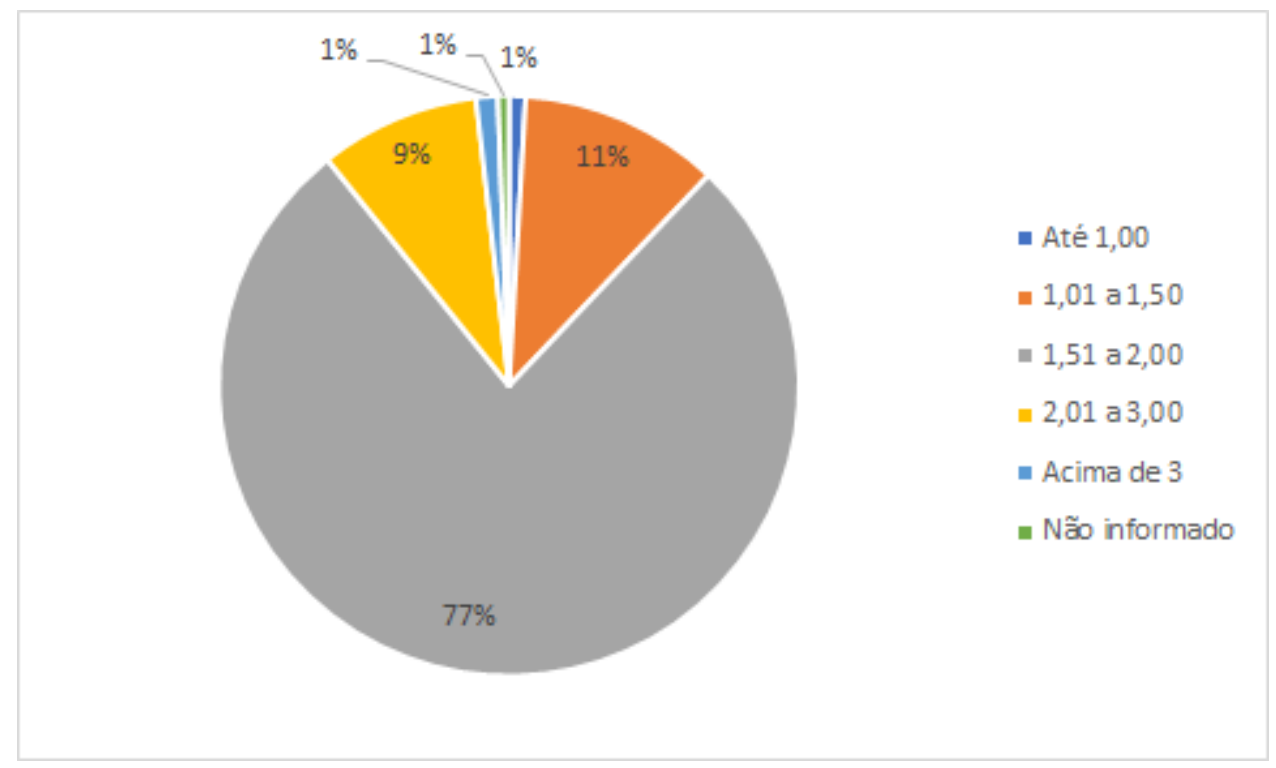

Fonte: Relação Anual de Informações Sociais (RAIS). Dados da pesquisa.

No RS, no mesmo ano, a remuneração dos trabalhadores estrangeiros foi um pouco superior, já que aproximadamente $70 \%$ dos imigrantes deles receberam até dois salários mínimos, ao passo que 19\% receberam entre dois e três salários mínimos e 12\% receberam mais de três salários. Essas informações demonstram que em outras regiões do estado os trabalhadores estrangeiros podem estar ocupando cargos melhores, em comparação à região do Vale do Taquari. Isso está 
diretamente relacionado ao grau de instrução, que também era superior no estado, assim como os setores de atuação mais diversificados.

Em termos de gênero, conforme demonstrado no Gráfico 7, pode-se observar que a preponderância é de trabalhadores estrangeiros masculinos, tanto na região como no estado, ao longo do período analisado. Inclusive, nota-se que em ambas as regiões o número de trabalhadores do sexo masculino aumentou na média do período, em comparação às trabalhadoras do sexo feminino. No Vale do Taquari, a redução das mulheres imigrantes no mercado de trabalho foi brusca de 2010 a 2012 , passando de $43 \%$ para $17 \%$, porém, gradativamente, o percentual foi aumentando nos anos seguintes. Em 2018, 35\% dos imigrantes registrados no mercado formal do VT eram mulheres, enquanto no RS esse percentual atingia $28 \%$.

Gráfico 7 - Gênero dos imigrantes internacionais com vínculo formal de trabalho no VT - 2010/2018

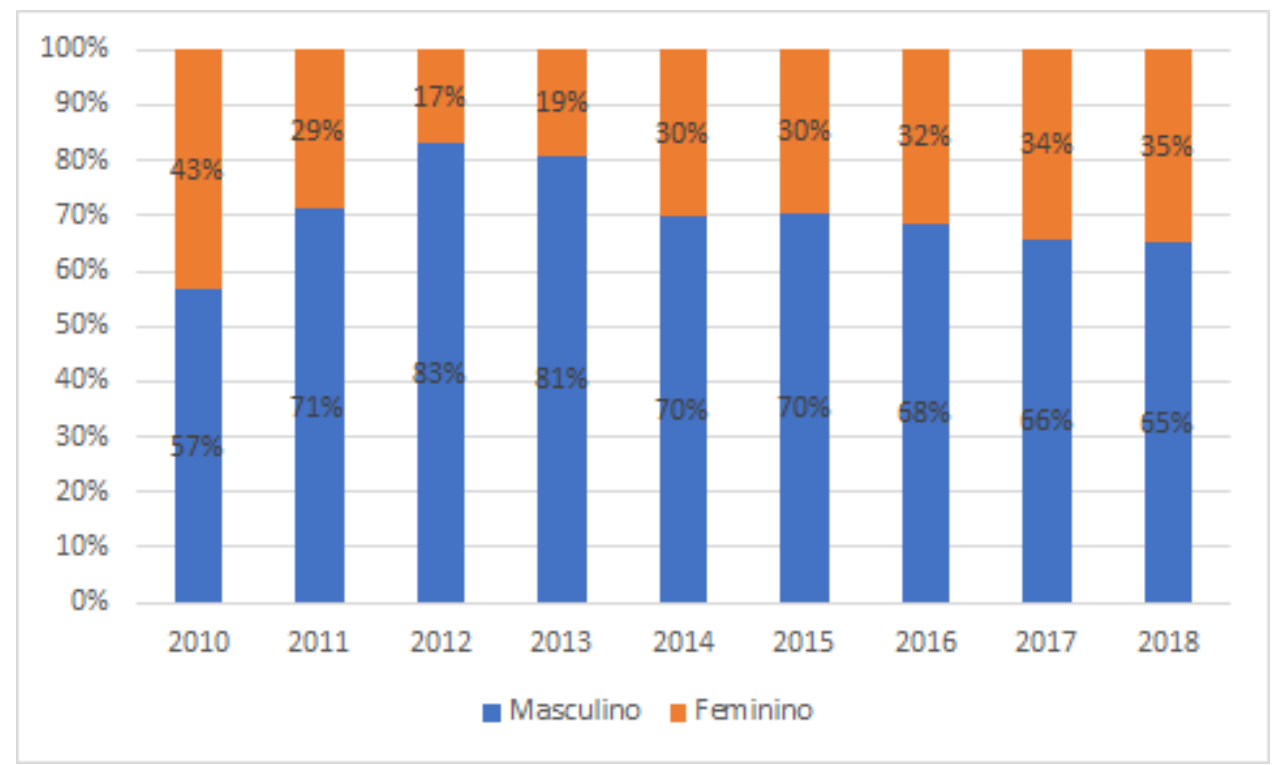

Fonte: Relação Anual de Informações Sociais (RAIS). Dados da pesquisa.

Verifica-se uma tendência de aumento gradativo da inserção de mulheres no mercado formal, orientando para uma feminilização da imigração (MARINUCCI, 2007), muito embora os dados empíricos da pesquisa mostram que, no início do período analisado, os homens predominavam no coletivo migratório. O tempo de análise para a experiência migratória laboral dentro desse novo perfil de contingente populacional é relativamente recente, por isso, pode-se analisar a partir da evolução anual. Com o passar dos anos, o número de mulheres foi aumentando, tanto em 
termos de reunião familiar como mulheres que migraram sozinhas. Ademais, cabe destacar que existem casos de mulheres (haitianas) que chegaram sozinhas e, mais tarde, depois de se capitalizarem, trouxeram marido e filhos.

Para avaliar o processo de aumento do fluxo da imigração feminina, analisouse o Relatório Anual das Migrações de 2018, o qual indica que o número de autorizações concedidas para mulheres cresceu 75\% em 2017, com relação ao ano de 2016. Porém, essa porcentagem correspondia apenas a 9\% do total das autorizações concedidas. Outro dado que pode contribuir para essa análise é o fato de que entre 2011 e 2018 foram registrados 492,7 mil imigrantes que ingressaram no Brasil por período superior a 1 ano, sendo 106,1 mil haitianos (CAVALCANTI; OLIVIERA; MACEDO, 2018). Destes, 61,4\% são homens, segundo o Relatório Anual das Migrações de 2019. Em 2018, no Brasil, os homens imigrantes, incluindo as diversas procedências, corresponderam a $72 \%$ das contratações e as mulheres a 28\% (CAVALCANTI et al., 2019).

Outra evidência empírica da pesquisa é o fato de as mulheres se depararem com maiores dificuldades para serem aceitas em empresas que mais contratam imigrantes na região em estudo. As organizações observaram que muitas mulheres chegam à região e logo engravidam a fim de obter o Registro Nacional de Estrangeiro, documento garantido pela legislação brasileira após nascimento de filho em solo brasileiro. Assim, podem residir e trabalhar indefinidamente no Brasil (MEJÍA; CAZAROTTO, 2017).

Sintetizando, a partir do estudo desenvolvido, observa-se que desde 2010 a região do Vale do Taquari tem atraído um contingente significativo de imigrantes laborais internacionais, especialmente haitianos. Essa atração está associada tanto à dinâmica da economia regional como também ao interesse de empresas locais que foram ao encontro de grupos de migrantes laborais em momentos de falta de mão de obra local.

\section{Considerações finais}

Desde o início do século XXI, observa-se que os fluxos migratórios internacionais voltaram a se intensificar, porém, na contemporaneidade, estão associados a novas dinâmicas que acompanham o crescimento econômico das regiões. O Brasil, nesse período, atraiu um contingente significativo de migrantes internacionais motivados por interesses econômicos, políticos, sociais, culturais, 
entre outros, especialmente associados à busca por melhores condições de vida e trabalho.

Essa tendência também foi observada na região do Vale do Taquari, analisada neste estudo, que desde 2010 tem recebido um contingente significativo de migrantes internacionais, especialmente haitianos. Diante desse cenário, o objetivo deste trabalho foi analisar a dinâmica laboral e o perfil dos trabalhadores imigrantes internacionais no mercado formal de trabalho na região do Vale do Taquari-RS.

Em relação à dinâmica laboral, observa-se que a região apresentou um crescimento das plantas da indústria de transformação, associado às cadeias agroalimentares, especialmente de abate de animais, processamento de carnes e processamento de laticínios, e também do setor de serviços. No entanto, em virtude da falta de mão de obra local, as indústrias atraíram, nos últimos anos, tanto migrantes nacionais como internacionais.

Aos migrantes estrangeiros, por falta de outras oportunidades, coube principalmente a ocupação de vagas que os nacionais não quiseram ocupar. Alguns, entretanto, arriscaram-se por novas perspectivas, retornando ao fluxo migratório internacional na busca de melhores oportunidades, no Chile e nos EUA, por exemplo. Porém, novas barreiras se apresentam e acabam retornando para a região.

Já em relação ao perfil, por meio do estudo identificou-se que os migrantes laborais empregados no Vale do Taquari são especialmente homens, em idade ativa e de escolaridade mediana, uma vez que a maioria apresenta até Ensino Médio completo. A renda média é um pouco inferior à renda média nacional, mas em consonância com o observado nos setores e na dinâmica laboral em que estão inseridos.

\section{REFERÊNCIAS}

BANCO CENTRAL DO BRASIL. Sistema Gerenciador de Séries Temporais: Taxa de câmbio - Livre - Dólar americano (venda) - diário. Disponível em: https://www3.bcb.gov.br/sgspub/localizarseries/localizarSeries.do?method=prepararTelaLoc alizarSeries, acesso em: 30 abr. 2020.

BARDEN, J. E. et al. A economia do Rio Grande do Sul no período entre 1920 e 1940: uma análise da região do Vale do Taquari. Estudo \& Debate, Lajeado, ano 8, n. 2, p. 7-55, 2001.

BARDEN, J. E. et al. Dinâmica populacional e transformações socioespaciais: uma análise a partir da região do Vale do Taquari/RS. Geosul, Florianópolis, v. 33, n. 66, p. 246-261, jan./abr. 2018. 
BÓGUS, L. M. M.; FABIANO, M. L. A. O Brasil como destino das migrações internacionais recentes: novas relações, possibilidades e desafios. Ponto e Vírgula, São Paulo, n. 18, p. 126-145, 2015.

BORJAS, G. J. Economia do trabalho. 5. ed. Porto Alegre: SMGH, 2012.

BORTOLETTI, V. S. Assolados pela crise, imigrantes deixam Encantado, Jornal Opinião, 12 ago. 2016. Disponível em: https://issuu.com/diogofedrizzi/docs/online12agosto2016. Acesso em: 10 out. 2019.

BRASIL. Ministério da Justiça e Segurança Pública. Portal de Imigração, 2019a. Disponível em: https://portaldeimigracao.mj.gov.br/pt/. Acesso em: 25 set. 2019.

BRASIL. Ministério da Economia. Relação Anual de Informações Sociais, 2019b. Disponível em: http://bi.mte.gov.br/bgcaged/login.php. Acesso em: 25 set. 2019.

CAVANCANTI, L; OLIVEIRA, T.; MACEDO, M. Resumo Executivo. Relatório Anual 2018. Observatório das Migrações Internacionais; Ministério do Trabalho/Conselho Nacional de Imigração e Coordenação Geral de Imigração. Brasília, DF: OBMigra, 2018. Disponível em: https://portaldeimigracao.mj.gov.br/images/publicacoes-obmigra/resumo-executivo2018.pdf. Acesso em: 15 jan. 2020.

CAVALCANTI, L. et al. Resumo executivo. Imigração e Refúgio no Brasil. A inserção do imigrante, solicitante de refúgio e refugiado no mercado de trabalho formal. Observatório das Migrações Internacionais; Ministério da Justiça e Segurança pública/Conselho Nacional de Imigração e Coordenação Geral de Imigração Laboral. Brasília, DF: OBMigra, 2019.

Disponível em: https://portaldeimigracao.mj.gov.br/images/publicacoesobmigra/RESUMO\%20EXECUTIVO\%20 \%202019.pdf. Acesso em: 15 jan. 2020.

CAZAROTTO, R. T.; MEJÍA, M. R. G. Repercussão socioespacial da imigração haitiana numa pequena cidade: o caso de Encantado - Rio Grande do Sul - Brasil. R. Ra'eGa, Curitiba, v. 45, p. 170-186, dez. 2018.

CHAPARINI, M. Dez haitianos chegam ao vale por semana, Jornal A Hora, 27 jul. 2019. Disponível em: https://www.jornalahora.com.br/2019/07/27/dez-haitianos-chegam-ao-valepor-semana/. Acesso em 27 out. 2019.

DAMIANI, A. L. População e geografia. 9. ed. São Paulo: Contexto, 2011.

FERREIRA, P. M. Migrações e Desenvolvimento. Lisboa: FEC: Fundação Fé e Cooperação, 2017.

GEORGE, P. As migrações internacionais. Lisboa: Dom Quixote, 1977.

GIL, A. C. Métodos e técnicas de pesquisa social. 7. ed. São Paulo: Atlas, 2019.

INSTITUTO BRASILEIRO DE GEOGRAFIA E ESTATÍSTICA - IBGE. Pesquisa Nacional por Amostra de Domicílios Contínua. 2019. Disponível em: https://www.ibge.gov.br/estatisticas/sociais/populacao/9173-pesquisa-nacional-por-amostrade-domicilios-continua-trimestral.html?t=resultados. Acesso em: 15 jan. 2020.

KENNETH, E. G.; VANDERKAMP, J. Repeat migration and disappointment. Canadian Journal of Regional Science, I Revue canadienne des sciences regionales, v. 3, n. IX, p. 299-322, 1986. 
MARINUCCI, R. Feminization of migration? REHMU: Revista Interdisciplinar da Mobilidade Humana, v. 15, n. 29, 2007.

MEJÍA, M. R. G.; CAZAROTTO, R. T. O papel das mulheres imigrantes na família transnacional que mobiliza a migração haitiana no Brasil. Revista Pós-Ciências Sociais, v. 14, p. $171,2017$.

MEJIA, M.R.G; CAZAROTTO, R.T; ROGÉRIO, M. S. O direito à cidade de migrantes contemporâneos: o caso de Lajeado - Rio Grande do Sul - Brasil. In: MEJIA, M. R. G (org.). Migrações e direitos humanos: problemática socioambiental. Lajeado: Ed. da Univates, 2018.

O INFORMATIVO do Vale. Haitianos chegam para trabalhar no Vale do Taquari, 16 out, 2012. Disponível em: https://www.informativo.com.br/geral/haitianos-chegam-para-trabalharno-vale-do-taquari,7876.jhtml. Acesso em: 19 nov. 2019.

PIORE, M. J. Birds of passage: migrant labor and industrial societies. Cambridge: Cambridge University Press, 1979.

PÓVOA NETO, H. Migrações internas e mobilidade do trabalho no Brasil atual. Novos desafios para análise. Experimental, n. 2, p. 11-24, 1997.

RAMOS, M. da C. Migrações, desenvolvimento e dinâmicas locais e regionai: grandes problemáticas do espaço europeu. Porto: FLUP, 2012. p. 63-102.

SASSEN, S. The mobility of labor and capital. Cambridge: Cambridge University Press, 1988.

SANTOS, Milton. A natureza do espaço: técnica e tempo, razão e emoção. São Paulo: Hucitec, 2006.

SASSEN, S. A criação de migrações internacionais. In: Sociologia da Globalização. Porto Alegre: Artmed, 2010. p. 113-138.

SAYAD, A. A imigração ou os paradoxos da alteridade. São Paulo: Edusp, 1998.

SCHILLER, N. C.; ÇAGLAR, A. Introduction: migrants and cities. In: SCHILLER, N.C.; ÇAGLAR, A. (orgs.). Locating migration: rescalling cities and migrants. New York: Cornell University, 2011.

TONHATI, T. et al. Os imigrantes haitianos no Brasil: a empregabilidade dos haitianos no mercado de trabalho brasileiro. In: CAVALCANTI, L. et al. (orgs.) A imigração haitiana no Brasil: características sócio-demográficas e laborais na região sul e no Distrito Federal. Santiago: OIM/Universidad de Desarrollo (UDD), 2016. p. 40-64. Disponível em: https://portaldeimigracao.mj.gov.br/images/publicacoes/A imigra\%C3\%A7\%C3\%A3o Haitia na no Brasil Caracter\%C3\%ADsticas Demogr\%C3\%A1ficas na regi\%C3\%A3o Sul e no Distrito Federal.pdf. 14 jan. 2020.

UEBEL, R. R. G. Análise do perfil socioespacial das migrações internacionais para o Rio Grande do Sul no início do século XXI: redes, atores e cenários da imigração haitiana e senegalesa. 2015. 248 f. Dissertação (Mestrado em Geografia) - Universidade Federal do Rio Grande do Sul, Porto Alegre, 2015. Disponível em:

https://www.lume.ufrgs.br/handle/10183/117357. Acesso em: 08. jan. 2020. 


\section{NOTAS DE AUTOR}

\section{CONTRIBUIÇÃO DE AUTORIA}

Rosmari Terezinha Cazarotto - Concepção. Análise de dados, Participação ativa da discussão dos resultados; Elaboração do manuscrito, revisão e aprovação da versão final do trabalho.

Fernanda Cristina Wiebusch Sindelar - Concepção. Coleta de dados. Análise de dados, e elaboração do manuscrito. Revisão e aprovação da versão final do trabalho.

\section{FINANCIAMENTO}

Este artigo é parte dos resultados do projeto de pesquisa Cidades médias e os fluxos imigratórios internacionais recentes: o exemplo da cidade de Lajeado na Região do Vale do Taquari-RS, financiado pelo CNPq (Conselho Nacional de Desenvolvimento Científico e Tecnológico) do Brasil no triênio 2019-2022 (processo 408687/2018-5), com apoio institucional da Univates.

\section{CONSENTIMENTO DE USO DE IMAGEM}

Não se aplica.

\section{APROVAÇÃO DE COMITÊ DE ÉTICA EM PESQUISA}

Não se aplica.

\section{CONFLITO DE INTERESSES}

Sem conflito de interesses.

\section{LICENÇA DE USO}

Este artigo está licenciado sob a Licença Creative Commons CC-BY. Com essa licença você pode compartilhar, adaptar, criar para qualquer fim, desde que atribua a autoria da obra.

\section{HISTÓRICO}

Recebido em: 11-02-2020

Aprovado em: 04-05-2020 